\title{
OBITUARY
}

\section{IN MEMORIAM GYÖRGY HAZAI}

(30.04.1932-07.01.2016)

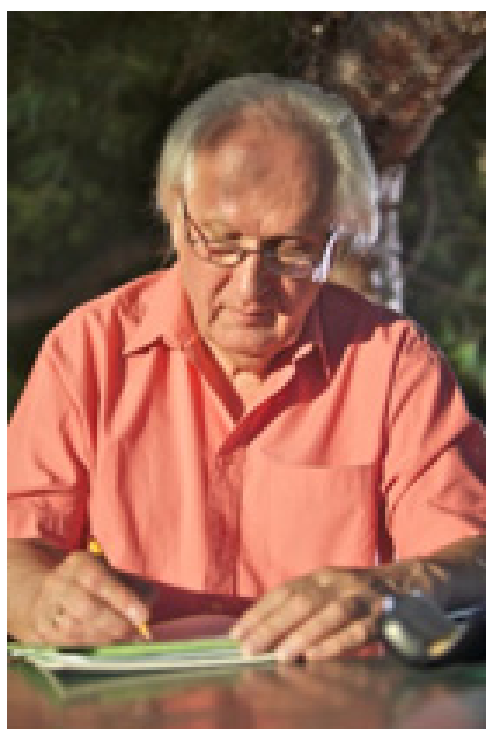

György Hazai ${ }^{1}$ ist im Alter von 83 Jahren von uns gegangen. Als Schüler von Gyula Németh, dem Altmeister der Turkologie an der Budapester Universität, prägte er die Turkologie, die „seine Wissenschaft“ werden sollte, in einem besonderen Maße, wenn auch vor allem in Städten anderer europäischer Länder, in Sofia, Berlin und Nicosia. Dennoch blieb er seiner Heimat stets verbunden, er war an verschiedenen Einrichtungen der Budapester Universität und vor allem an der Ungarischen Akademie der Wissenschaften tätig.

Als Assistent mit 24 Jahren übernahm György Hazai 1956 seine erste Lehrtätigkeit in Sofia. Der Mut, neue Aufgaben zu übernehmen, hat ihn zeit seines Lebens nicht verlassen. Bereits Ende der 50er Jahre ergab es sich, daß er sich für eine größere Aufgabe rüstete, als er auf Anraten des Finnougristen Wolfgang Steinitz nach Berlin berufen wurde, wo er ab 1963 an der Humboldt-Universität eine neue Generation von Turkologen auszubilden begann, von denen später einige auch in der Turfan-For-

${ }^{1}$ Nach ungarischem Brauch natürlich Hazai György. In seinen nicht-ungarischen Veröffentlichungen ist der Vorname in verschiedenen Formen entsprechend der Sprache des Aufsatzes verzeichnet: Georges, Georg, oft aber auch György (in einem französischen Beitrag Gyorgy), abgekürzt G. oder Gy., doch stets vor dem Familiennamen. Um sich und anderen das praktische Leben in Berlin zu erleichtern, benutzte er mündlich eine deutsche Aussprache „Hatsa-i““. 
schung ihr Betätigungsfeld fanden. Es gelang ihm mit viel Geschick und mit Unterstützung von A. v. Gabain, vor allem aber auch unter Einbeziehung japanischer Buddhologen der Ryūkoku-Universität für die Identifizierung chinesischer Turfantexte, der Turfan-Forschung am Institut für Orientforschung der Berliner Akademie ${ }^{2}$ und am späteren Zentralinstitut für Alte Geschichte und Archäologie einen geachteten Platz in der Wissenschaftslandschaft der DDR zu verleihen. Wie György Hazai den Aufbau oder besser gesagt die Wiederbelebung der Turfan-Forschung selbst sah, hat er in seinem Beitrag „Die Rolle der Deutschen und Ungarn bei der Erforschung Zentralasiens“ auf einem 2010 veranstalteten Kolloquium dargelegt. ${ }^{3}$ Als Lehrer an der HumboldtUniversität hat er einige Generationen von Turkologen betreut, und für viele erwuchs daraus eine berufliche Perspektive. Er ließ die Studenten an seinen wissenschaftlichen Interessen und Aufgaben teilhaben, gab Anregungen in vielfacher Hinsicht und förderte Ideen, die erfolgversprechend waren.

Auf diese Berliner Zeit, nahezu 20 Jahre, folgte ab 1982 in Budapest eine Periode, in der er als Direktor des Ungarischen Akademie-Verlags ${ }^{4}$ in verantwortungsvoller Weise bemüht war, die orientalististischen Belange zu fördern.

1992 übernahm György Hazai eine keineswegs leichtere Aufgabe in Zypern. Es oblag ihm, ein Department of Turkish Studies an der University of Cyprus auf- und auszubauen. Mit viel Elan und Mut war er dort bis 1999 tätig.

Erwachsen aus seiner Berliner Zeit sind die Beziehungen zum Klaus Schwarz Verlag, der jetzt von Gert Winkelhane geführt wird. Die von György Hazai begründete Reihe „Studien zur Sprache, Geschichte und Kultur der Türkvölker“ begann 1980. Als Band 14 erschien 2012 eine Sammlung von Arbeiten von György Hazai unter dem Titel „Monumenta et Studia Turcologica“ mit einem umfangreichen Index, der den Einstieg zu György Hazais wissenschaftlichen Aufsätzen sehr erleichtert. In der Einleitung zu diesem Band haben die Herausgeber bereits einen Überblick über die Arbeitsfelder Hazais gegeben: Turkologie und osmanische Geschichte einschließlich historischer Urkunden, Osmanische und türkeitürkische Sprachgeschichte, Transkriptionstexte, Dialekte und Alttürkische Studien, die das Lebenswerk Hazais ausmachen. ${ }^{5}$ Die im Band enthaltene Bibliographie ${ }^{6}$ wird mit den nach 2012 erschienenen Arbeiten aufzufüllen sein, was zu gegebener Zeit getan werden kann.

\footnotetext{
${ }^{2}$ Vgl. dazu G. Hazai, Intensivierung der Turfan-Forschung. Mitteilungen des Instituts für Orientforschung 14, 1968, S. 127-128.

${ }^{3}$ Publiziert in Kellner-Heinkele, B. - Raschmann, S.-Chr. - Schönig, C. - Winkelhane, G. Zieme P. (Hrsg.): Monumenta et Studia Turcologica. Ausgewählte Schriften von György Hazai. Berlin, 2012, S. 35-40.

${ }^{4}$ Akadémiai Kiadó, Budapest.

${ }^{5}$ Kellner-Heinkele, B.-Raschmann, S.-Chr.-Schönig, C.-Winkelhane, G.-Zieme P. (Hrsg.): Monumenta et Studia Turcologica. Ausgewählte Schriften von György Hazai. Berlin, 2012, S. $14-18$.

${ }^{6}$ Kellner-Heinkele, B.-Raschmann, S.-Chr.-Schönig, C.-Winkelhane, G.-Zieme P. (Hrsg.): Monumenta et Studia Turcologica. Ausgewählte Schriften von György Hazai. Berlin, 2012, S. $684-719$.
} 
György Hazai war ein professioneller und leidenschaftlicher Bibliograph, wie schon seine Sovieto-Turcica von $1960^{7}$ zeigten. Auch seine wissenschaftlichen Studien über bibliographische und dokumentarische Tätigkeiten hatten stets im Blick, welchen Beitrag diese für die Fortentwicklung der Turkologie leisten können. Seine diesbezüglichen Bücher, meist in Zusammenarbeit mit Barbara Kellner-Heinkele entstanden, gelten heute bereits als wichtige Publikationen, die den Zugang zu den Quellen ermöglichen. Dem Turkologischen Anzeiger hat er mit nicht nachlassendem Engagement die Existenz gesichert.

György Hazai hat in vielfältiger Weise an der Übersetzung und Vermittlung moderner türkischer Literatur in Ungarn mitgewirkt, wofür stellvertretend die Anthologie „A szenvedélyek tengere“ genannt sein möge. ${ }^{8}$ Unterstützung fand er dafür bei türkischen Dichtern und Schriftstellern.

Er widmete sich ergiebig dem Leben und Wirken von Ármin Vámbéry, schon sehr früh mit einer Bibliographie sowie später mit der Herausgabe seiner Werke und einigen Studien.

Wenn auch schon oft genannt, sei hier wiederholt, daß ihm 1971 mit dem Start der Reihe „Berliner Turfantexte“ ${ }^{\natural 9}$ ein Meisterstück gelang, an dessen Fortsetzung nicht nur Turkologen, sondern Vertreter weiterer Fächer beteiligt sind, die sich dem Studium der Texte der vorislamischen zentralasiatischen Texte gewidmet haben. Der 37. Band der Reihe, eine Edition der altuigurischen Fragmente der Daśakarmapathāvadānamālā durch Jens Wilkens ${ }^{10}$, macht erneut die vielfältigen Verknüpfungen der Kulturen von West und Ost an der Seidenstraße sichtbar.

Die Permanent International Altaistic Conference, die 1969 in Berlin unter komplizierten Bedingungen von György Hazai organisiert wurde, war schon durch die unglaublich starke Beteiligung sowjetischer Turkologen ein Erfolg. So kamen zum ersten Mal sehr viele Wissenschaftler aus Ost und West zu einem Meinungsaustausch zusammen. Nur wenige Jahre nach dem Mauerbau kann man diese Tagung als eine wissenschaftspolitische Glanzleistung nicht überbewerten. Der 1974 erschienene Tagungsband vermittelt nur einen begrenzten Einblick in den Ablauf dieses bedeutsamen Ereignisses.

$\mathrm{Ab} 2000$ richtete er seinen Hauptsitz in Budapest ein, als er zum Gründungsrektor der Andrássy-Universität berufen wurde. Abgesehen von zahlreichen Gastreisen setzte er hier in Budapest seine wissenschaftlichen Untersuchungen zu einst begonnenen Textausgaben altosmanischer Werke fort und konnte mehrere Publikationen fertigstellen. Neben den Editionen einer anonymen Übersetzung des Tazkaratu'l-Awliyā von

${ }^{7}$ Sovieto-Turcica. Beiträge zur Bibliographie der türkischen Sprachwissenschaft in russischer Sprache in der Sowjetunion 1917-1957 (Bibliotheca Orientalis Hungarica 9). Budapest, 1960.

${ }^{8}$ Szenvedélyek tengere. A török költészet antológiája [Meer der Leidenschaften. Anthologie der türkischen Dichtung]. Budapest, 1961.

${ }^{9}$ Berliner Turfantexte I. Berlin, 1971.

${ }^{10}$ Buddhistische Erzählungen aus dem alten Zentralasien. Edition der altuigurischen Daśakarmapathāvadānamālā, 1-3 (Berliner Turfantexte 37). Turnhout, 2016. 
Farīduddīn 'Aț̣āar ${ }^{11}$ und der Geschichte der Ungarn in einer osmanischen Chronik des 16. Jahrhunderts ${ }^{12}$ ist das Ferec ba'd eş-şidde $e^{13}$ von besonderer Bedeutung, denn dieser Text gehört zu den Basistexten des „Etymologischen und Historischen Wörterbuchs" von Andreas Tietze, mit dem ihn eine jahrzehntelange Zusammenarbeit verband.

Mit seinem Wirken in zahlreichen internationalen Organisationen hat er wichtige Beiträge zur Förderung der Turkologie im besonderen und der Orientalistik im allgemeinen geleistet. In ihrer Laudatio formulierte Barbara Kellner-Heinkele es so: „György Hazai ist nicht nur ein Weltbürger, wenn wir seine biographische Flexibilität und die unzähligen Meilen berücksichtigen, die er über die Jahrzehnte für die Wissenschaft gereist ist. Schon immer hat er sich auch als einer verstanden, der Brücken schlägt, Menschen und Ideen zusammenbringt und jenseits von politischen Empfindlichkeiten wissenschaftliche Kooperation befördert. In den Berliner Jahren konnte er mit Hilfe der ungarischen Botschaft tun, was wenigen zwischen den politischen Blöcken möglich war, nämlich regelmäßig von Ost- nach Westberlin zu kommen, wo ihn insbesondere eine verlässliche Freundschaft mit Bibliotheksdirektor Dr. Wolfgang Voigt, dem Initiator des Unternehmens ,Katalogisierung der Orientalischen Handschriften in Deutschland', verband. Von West-Berlin aus konnten Verbindungen in alle Welt gepflegt, Bücher und Nachrichten von Ost nach West und von West nach Ost expediert und Literatur für die eigenen wissenschaftlichen Arbeiten eingesehen werden." ${ }^{\prime 14}$

$\mathrm{Zu}$ seinem 65. Geburtstag haben Schüler, Freunde und Kollegen eine Festschrift unter dem Titel „Studia Ottomanica“"15 herausgegeben.

Das Akademienvorhaben „Turfanforschung“ an der Berlin-Brandenburgischen Akademie der Wissenschaften ist sich der großen Verdienste des Gelehrten bewußt und hat 2012 anläßlich seines 80. Geburtstages ein Deutsch-Ungarisches Kolloquium in Berlin veranstaltet. Dessen Beiträge wurden als „Opuscula György Hazai Dicata“"16 vom Klaus Schwarz Verlag publiziert. Die Berliner Kollegen konnten pünktlich seine Gesammelten Schriften als „Monumenta et Studia Turcologica“ überreichen. Auch dieser Band wurde vom Klaus Schwarz Verlag in Berlin betreut. ${ }^{17}$

${ }^{11}$ Die altanatolisch-türkische Übersetzung des Tažkaratu'l-Awliyā von Farīduddīn 'Atțāar. Berlin, 2008.

${ }^{12}$ Die Geschichte der Ungarn in einer osmanischen Chronik des 16. Jahrhunderts: Tercümān Mahmūds Tārīhn-i Ungurus. Berlin, 2009.

${ }^{13}$ Hazai, György - Tietze, Andreas: Ferec ba 'd eş-şidde. Freud nach Leid. Ein frühosmanisches Geschichtenbuch. Berlin, 2006.

${ }^{14}$ Kellner-Heinkele, B.: Laudatio. In: Kellner-Heinkele, B.-Raschmann, S.-Chr. (Hrsg.): Opuscula György Hazai Dicata. Beiträge zum Deutsch-Ungarischen Workshop aus Anlass des 80. Geburtstages von György Hazai. Berlin, 2015, S. 23-24.

${ }^{15}$ Kellner-Heinkele, B. - Zieme, P. (Hrsg.): Studia Ottomanica. Festgabe für György Hazai zum 65. Geburtstag (Veröffentlichungen der Societas Uralo-Altaica 47). Wiesbaden, 1997.

${ }^{16}$ Kellner-Heinkele, B. - Raschmann, S.-Chr. (Hrsg.): Opuscula György Hazai Dicata. Beiträge zum Deutsch-Ungarischen Workshop aus Anlass des 80. Geburtstages von György Hazai. Berlin, 2015.

${ }^{17}$ Kellner-Heinkele, B.-Raschmann, S.-Chr.-Schönig, C.-Winkelhane, G.-Zieme P. (Hrsg.): Monumenta et Studia Turcologica. Ausgewählte Schriften von György Hazai. Berlin, 2012. 
György Hazai, Ordentliches Mitglied der Ungarischen Akademie der Wissenschaften $^{18}$, Mitglied der Academia Europaea ${ }^{19}$, Ehrenmitglied der Türkischen Akademie $^{20}$ sowie Ehrenmitglied weiterer wissenschaftlicher Institutionen, ist mit zahlreichen Ehrungen und Auszeichnungen bedacht worden. Das Große Verdienstkreuz des Verdienstordens der Bundesrepublik Deutschland (2004), das Köztársasági Érdemrend középkeresztje (2005) und der Commandeur de l'Ordre de Merite (2007) zeigen, daß György Hazai für seine Verdienste um die Förderung der Orientalistik und der Geisteswissenschaften europaweit allgemein große Anerkennung erlangt hat.

$\mathrm{Ob}$ Schüler, Freunde oder Mitstreiter, das Andenken an den Gastprofessor, an den Wissenschaftler und Kollegen werden alle wachhalten. György Hazai hat mit seinen wissenschaftlichen Arbeiten und mit seinem Engagement für die Förderung der Wissenschaften in der Geschichte der Turkologie und Orientalistik europa- und weltweit einen bleibenden Platz.

Peter Zieme

\footnotetext{
${ }^{18}$ Magyar Tudományos Akadémia, s. http://mta.hu/i-osztaly/elhunyt-hazai-gyorgy-turkologusorientalista-az-mta-rendes-tagja-105618.

${ }^{19} \mathrm{~S}$. http://www.ae-info.org/ae/User/Hazai_Gy\%C3\%B6rgy.

${ }^{20}$ Türkiye Bilimler Akademisi, s. http://www.tuba.gov.tr/news/tuba-seref-uyesi-prof-drgyorgy-hazai-vefat-etti/id/1428.
} 
